\title{
EFFECTS OF STRAIN RATE ON WORK HARDENING OF HSLA AND Ti-IF STEELS
}

\section{Notation:}

A - constant

$b$ - Burger's vector, $\mathrm{nm}, \mu \mathrm{m}, \mathrm{mm}, \mathrm{cm}$

$B^{-}$a coefficient dependent on the chemical composition and strain rate and directly correlates to the stage of austenite decomposition

$c_{1 \ldots 5}-$ Zerilli - Armstrong model's constants

$d$ - grain size, $\mu \mathrm{m}, \mathrm{mm}$

$D$ - Cowper-Symonds coefficient

$f$ - the volume fraction of precipitates (for Nb-microalloyed steels: $f=1.13 \cdot 10^{-4}[N b]$ )

$G$ - shear modulus, MPa

$K$ - microstructural stress intensity, MPa

$k$ - Boltzmann's constant, J/K

$K_{p}$ - dispersion strengthening contribution coefficient

$k_{s}$ - constant associated with subgrain boundary strength

$\Delta l$ - the distance between dislocation barriers

$M$ - orientation factor

$[M]$ - chemical composition

$n$ - hardening exponent

$P$ - constant dependent on ferrite grain size, MPa

* Ph.D., **Ph.D., D.Sc.; *** M.Sc.: Faculty of Metals Engineering and Industrial Computer Science, AGH University of Science and Technology, Cracow, Poland

mstefans@metal.agh.edu.pl; majta@metal.agh.edu.pl;kmuszka@metal.agh.edu.pl 


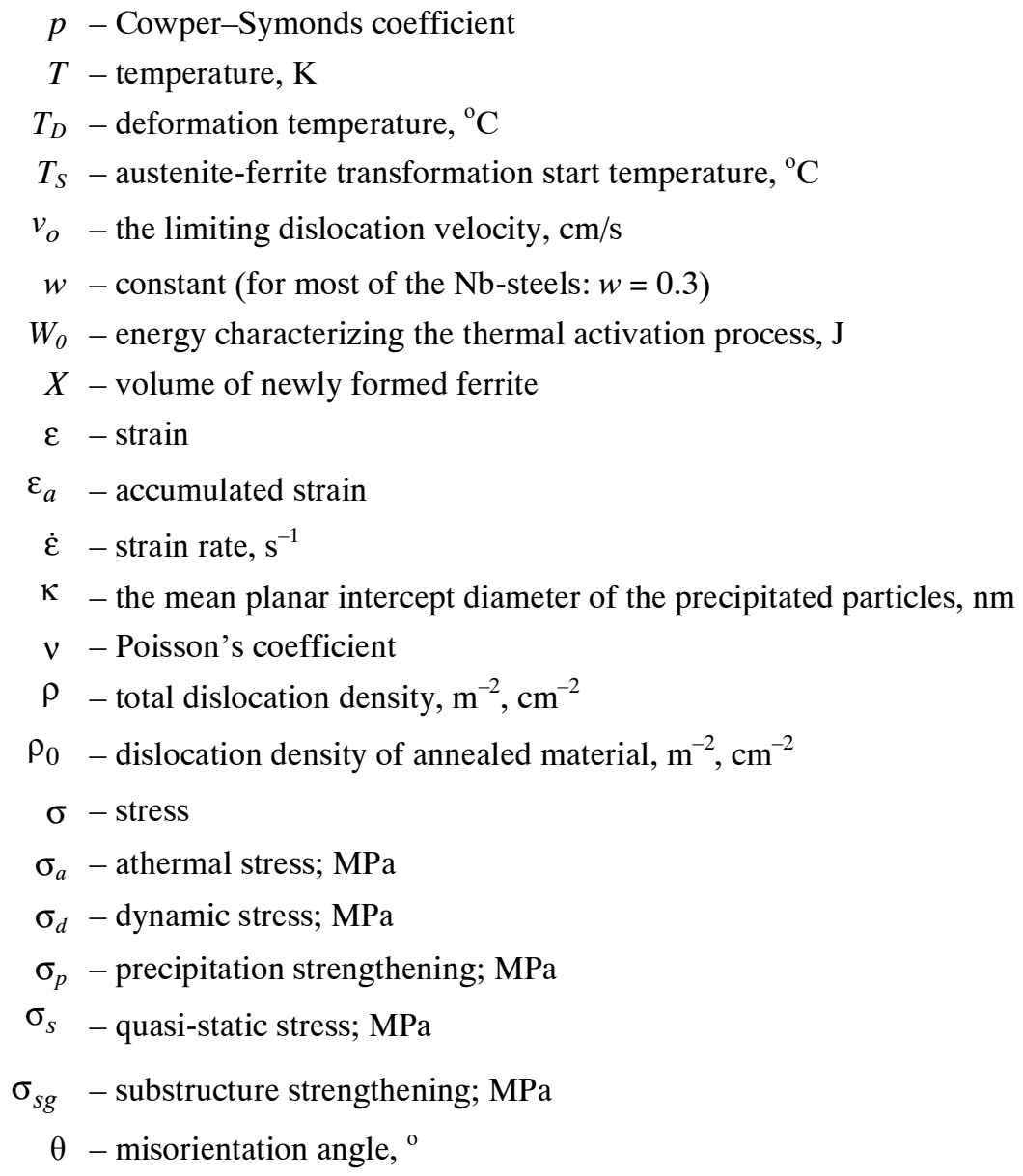

\section{INTRODUCTION}

The microalloyed HSLA and Ti-IF steels aimed for automotive industry have been of great interest for many years for the sake of their promising high strain rate performance with a high-energy absorption. The dynamic behavior of such materials is still the subject of extensive research. The steel hardening results from different strengthening mechanisms. The situation is more complex, whenever high strain rate of deformation is applied. It is difficult to describe material behavior during deformation at high strain rates using general, "universal" method of analysis. For example, mechanical twinning as a plastic deformation mechanism should be considered in addition to dislocation motion. The proper description of correlations among high strain rate and mechanical and microstructural behavior of the material are very important issues, not only because of the final products implementations, but also with respect to the manufacturing process. It has been determined that in many metal forming processes (drawing, rolling of long products, forging) the strain rates in the 
deformation zones are very high (up to $4000 \mathrm{~s}^{-1}$ ). It is, therefore, clear that the influence of strain rate in modeling of such metal forming processes should be taken into account. There is a number of ideas that have been proposed and successfully employed to describe the mechanical behavior and microstructural evolution as a function of strain rate. The purpose of this paper is to present the mechanical and microstructural response of microalloyed steels subjected to dynamic (i.e. at very high strain rates, not considering mass forces) deformation in cold forming conditions.

\section{EXPERIMENTAL PROCEDURES}

Axisymmetrical compression tests were performed in order to study the effect of high strain rates on the material mechanical and microstructural behavior. The compression tests were carried out under various strains and strain rate conditions at room temperature. The evolution of the microstructure, as well as the mechanical response of the material affected by the strain rate, strain and generated heat, were observed and analyzed. The tests were performed using the tensile-compression testing machine ( strain rate $=0.001 \mathrm{~s}^{-1}$ ), dropweight (strain rate $=200,400,600,800 \mathrm{~s}^{-1}$ ), Schenck servo-hydraulic compression testing machine ( strain rate $=150 \mathrm{~s}^{-1}$ ) and the Split Hopkinson Pressure Bar $\left(\right.$ strain rate $=2500 \mathrm{~s}^{-1}$ ). The tests scheme and the basic chemical compositions of the investigated steels (in wt. \%) are shown in Figure 1a and Table 1, respectively.

a)

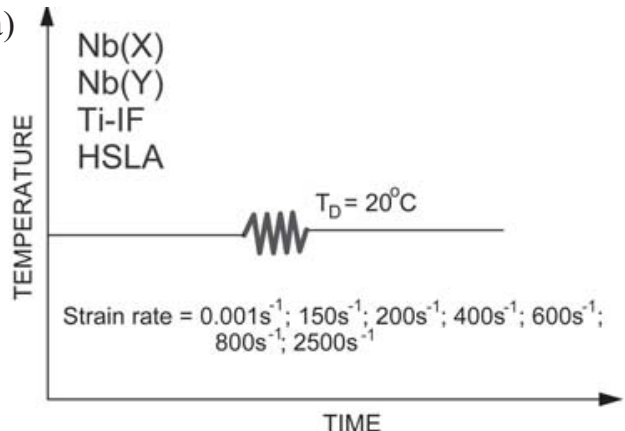

b)

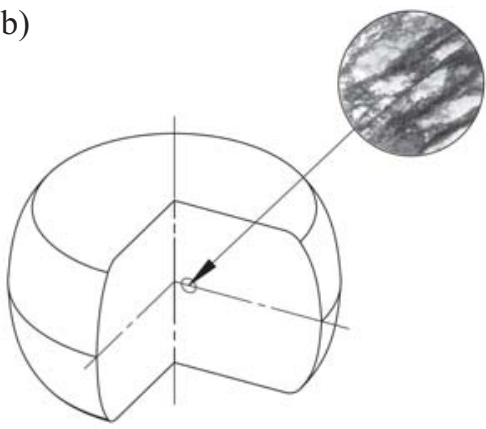

Fig. 1. The scheme of compression tests (a), the location of TEM observations (b)

Table 1. The chemical compositions (in wt. \%) of investigated steels

\begin{tabular}{||c|c|c|c|c|c|c|c|c|c|c||}
\hline \hline Steel & $\mathrm{C}$ & $\mathrm{Mn}$ & $\mathrm{Si}$ & $\mathrm{Al}$ & $\mathrm{Ti}$ & $\mathrm{S}$ & $\mathrm{N}$ & $\mathrm{P}$ & $\mathrm{Nb}$ & $\mathrm{B}$ \\
\hline $\mathrm{Ti}-\mathrm{IF}$ & 0.0022 & 0.112 & 0.009 & 0.037 & 0.073 & 0.006 & 0.0034 & 0.009 & - & - \\
\hline $\mathrm{HSLA}$ & 0.067 & 1.3 & 0.34 & 0.037 & 0.024 & 0.006 & 0.0054 & 0.015 & 0.076 & - \\
\hline $\mathrm{Nb}(\mathrm{Y})$ & 0.07 & 1.36 & 0.27 & 0.02 & 0.031 & 0.006 & 0.0098 & 0.015 & 0.067 & 0.003 \\
\hline $\mathrm{Nb}(\mathrm{X})$ & 0.1 & 1.5 & 0.25 & 0.029 & 0.113 & 0.009 & 0.011 & 0.014 & 0.05 & 0.032 \\
\hline \hline
\end{tabular}


The transmission electron microscopy (TEM) was used to examine the microstructures of investigated steels after dynamic compression tests. The place of taking a specimen for TEM is shown in Figure 1b. Finally, hardness measurements (HV5) were carried out using Zwick hardness tester.

\section{RESULTS}

In the present analysis, the application of a wide range of strain rates makes possible to evaluate the strain rate sensitivity of studied materials and its influence on microstructure evolution and, in consequence, on mechanical properties. Based on the results of present study it can be stated that the change in loading conditions from quasi-static to dynamic causes significant discrepancies in microstructure evolution and in the hardening of final material. These effects are reflected in the final mechanical properties (e.g. hardness). The discrepancies between microstructures of materials deformed under quasi-static and dynamic conditions can be observed in all of investigated in present study steels.

a)

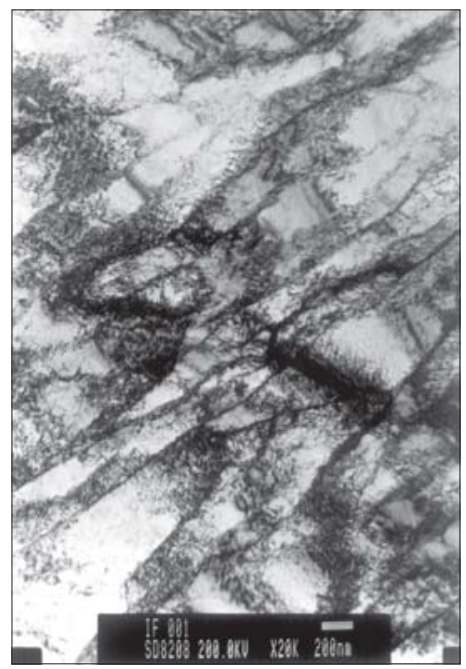

b)

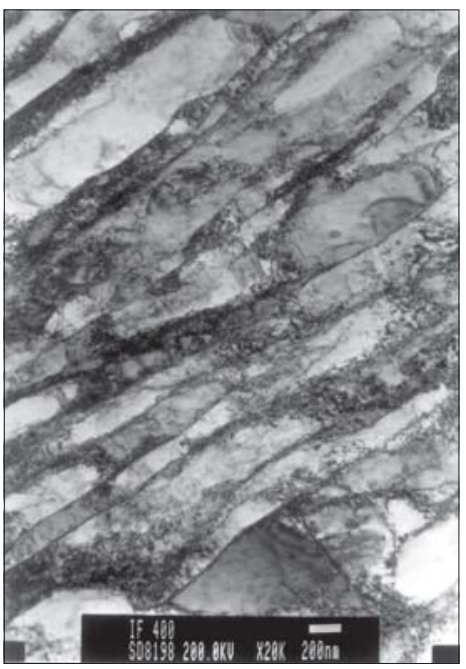

Fig. 2. Transmission electron micrographs of Ti-IF steel after quasi-static (a) and dynamic (b) compression tests at room temperature. Strain rate 0.001 and $400 \mathrm{~s}^{-1}$, respectively

In the samples deformed under quasi-static conditions (Figs $2 \mathrm{a}$ and $3 \mathrm{a}$ ), the tendency to form the cell structure is visible, although the cell walls are weakly outlined. The higher and lower dislocation density areas can also be seen. It can be noticed that microalloyed steel (Fig. 3a) shows more scattered dislocation structure. In the case of Ti-IF steel (Fig. 2b), increased strain rate and strain cause more refined and more clearly oriented structure. Observed structures are refined due to decreased spacing between the lamellar boundaries. Dislocation cells observed in the $\mathrm{Nb}(\mathrm{Y})$ steel (Figure $3 \mathrm{~b}$ ) are smaller and more clearly outlined comparing to the Ti-IF steel samples. However, it should be mentioned that in this case it is a result of coarsed initial structure of Ti-IF steel (100 $\mu \mathrm{m}$ comparing to $12 \mu \mathrm{m}$ grain diameter of $\mathrm{Nb}(\mathrm{Y})$ steel). 
a)

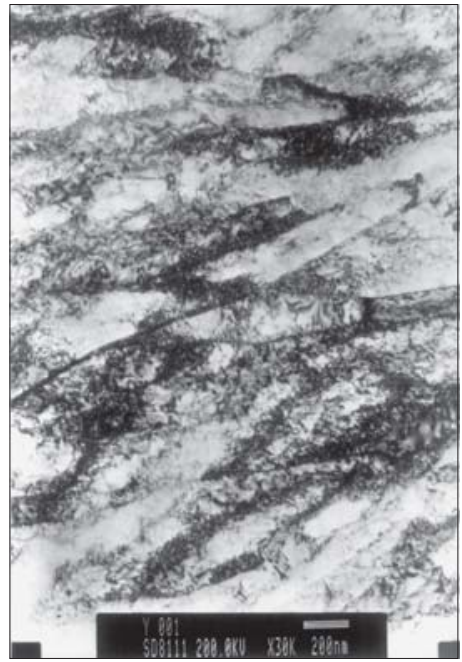

b)

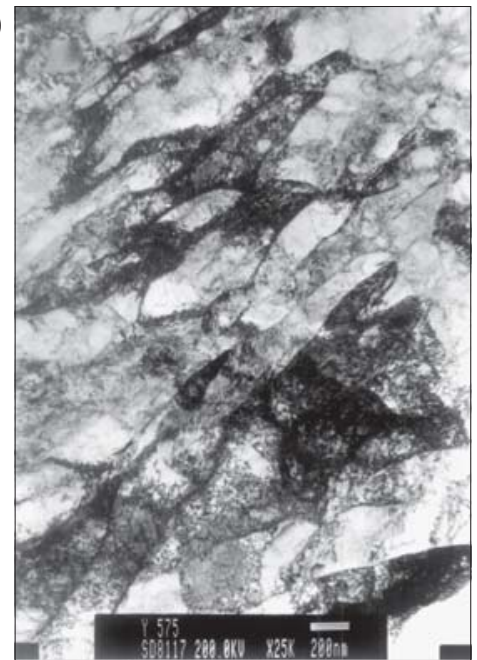

Fig. 3. Transmission electron micrographs of $\mathrm{Nb}(Y)$ steel after quasi-static (a) and dynamic (b) compression tests at room temperature. Strain rate 0.001 and $600 \mathrm{~s}^{-1}$, respectively

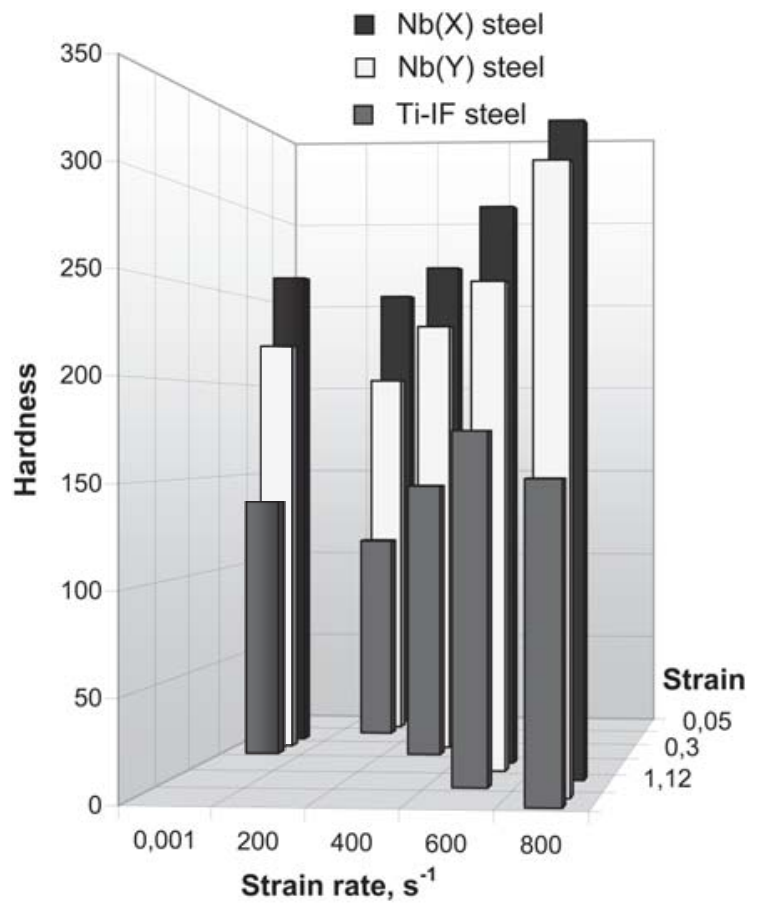

Fig. 4. Variations of hardness with strain and strain rates at room temperature. Notice increased hardness for higher strain rates [1]
The results shown in Figure 4 represent very interesting behavior of the investigated steels. It can be seen that influence of strain rate on mechanical properties is observed in each case of the tests, despite of history of deformation process. It can be observed that applied high strain rate directly influences the hardness. The chemical compositions of investigated steels do not change this correlation significantly. It can not be clearly stated, at present stage of study, that high strain rate is the only reason causing observed differences in hardness measurements. However, we can suppose that high strain rates affect the dislocation activity and finally influence on strengthening mechanisms. 


\section{MODELLING}

One of the fundamental principles of thermomechanical processing is the simultaneous use and superposition of microstructural evolution and mechanical behavior of the deformed material. The degree of generated defects, cracks and phase transformation is decisive for the final microstructure to be continuous, partially fractured, or fully fractured. It is well known that the yield stress in the metallic materials increases steeply above a critical strain rate (4000 $\mathrm{s}^{-1}$ for mild steel) [2]. Following Meyers, the principle short-range barrier is the Peierls-Nabarro stress, which is especially important for b.c.c. structures. For f.c.c. and h.c.p. metals, dislocation forests are the primary short-range barriers at lower temperatures. The different nature of these barriers is responsible for the major differences in strain rate sensitivity between f.c.c. and b.c.c. phases.

The materials models are frequently used for extrapolation of the flow stress to very high strain rates. However, it is generally very difficult to determine mechanical response of the material due to the complex microstructural behavior that occurs during high strain rate loading. There are several models enabling reasonably good description of the flow stress which take into consideration strain rate effects.

The most frequently cited in the literature are:

- Cowper-Symonds [3]

- Johnson-Cook [4]

- Zerilli-Armstrong [5]

- MTS (mechanical threshold stress) [6]

The Cowper-Symonds equation is one of the simplest model of material behavior at different strain rates

$$
\frac{\sigma_{d}}{\sigma_{s}}=1+\left(\frac{\dot{\varepsilon}}{D}\right)^{\frac{1}{p}}
$$

where:

$D$ and $p$ - Cowper-Symonds coefficients,

$\dot{\varepsilon}$ - strain rate,

$\sigma_{d}-$ dynamic stress,

$\sigma_{\mathrm{s}}-$ quasi-static stress.

One of the limitation of this model is that it does not include temperature and strain hardening effects. The calculated coefficients in Eq. (1) are presented in Figure 5b.

The results of calculated and measured flow stress (Fig. 5b) reflect the behavior similar to these observed by Campbell and Ferguson (Fig. 5a). For lower strain rate a linear stress dependence is observed. For higher strain rate (above $10^{3} \mathrm{~s}^{-1}$ ) significant increase in yield strength is exhibited.

The Johnson-Cook empirical constitutive equation is based on experimentally determined coefficients. This approach does not incorporate the structural response of deformed material and can be replaced by dislocation-based models such as the Zerilli-Armstrong and the mechanical threshold stress (MTS). 
a)

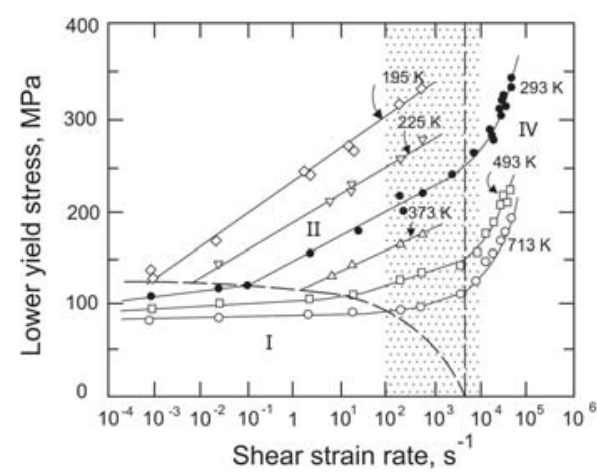

b)

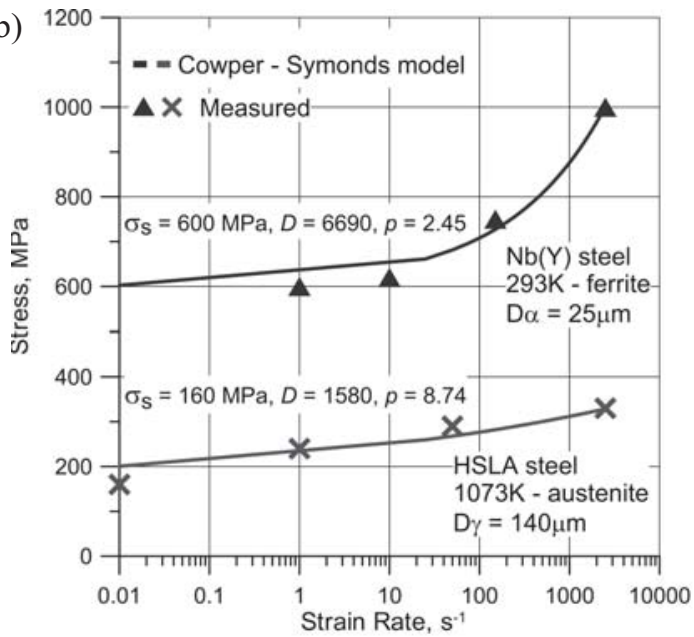

Fig. 5. Experiment data by Campbell and Ferguson [2] (a), comparison of calculated (CowperSymonds model) and measured flow stress of microalloyed steels [1, 7] (b)

In the present study, the Zerilli-Armstrong model has been chosen and modified. This model is one of the simplest dislocation mechanics formulations and was proposed in 1987 by Zerilli and Armstrong. Authors, based on the idea of the thermally activated motion of dislocations, proposed the microstructurally based constitutive model that is adequate for two-phase structure and dynamic loading. Armstrong also pointed out the importance of certain athermal effects due to grain size and related deformation twinning to be treated separately and explicitly.

The nature of the dislocation interactions leads to different forms of equation for the f.c.c. and b.c.c. structures. For b.c.c. metals, the motion of dislocations is governed by Peierls-Nabarro stress and it is resulting from the interaction produced by the overall lattice potential. This leads to a little increase in the flow stress with strain. For f.c.c. metals the motion of dislocations is constrained by their mutual intersections leading to substantial strain hardening.

Complete constitutive relation for f.c.c. metals is

$$
\sigma=\sigma_{a}+c_{2} \varepsilon^{1 / 2} \exp \left(-c_{3} T+c_{4} T \ln \dot{\varepsilon}\right)+K d^{-1 / 2}
$$

For b.c.c. metals an additional empirical term of the form $c_{5} \varepsilon^{n}$ is added to describe the strain dependence

$$
\sigma=\sigma_{a}+c_{1} \exp \left(-c_{3} T+c_{4} T \ln \dot{\varepsilon}\right)+c_{5} \varepsilon^{n}+K d^{-1 / 2}
$$

To increase an accuracy of the model for b.c.c. material, the precipitation and substructure strengthening description is incorporated into it. This is especially important in the case of microalloyed steels. Hence, Eq. (3) has a form

$$
\sigma=\sigma_{a}+c_{1} \exp \left(-c_{3} T+c_{4} T \ln \dot{\varepsilon}\right)+c_{5} \varepsilon^{n}+K d^{-1 / 2}+\sigma_{p}+\sigma_{s g}
$$


All constants and coefficients of modified Zerilli-Armstrong model of Ti-IF and microalloyed steels (equations (2) and (4)) are summarized in Table 2.

Table 2. Constants and coefficient of modified Zerilli-Armstrong model

\begin{tabular}{|c|c|c|c|}
\hline \multirow{2}{*}{ Constant } & \multicolumn{2}{|c|}{ Value } & \multirow{2}{*}{ Literature } \\
\hline & Ferrite & Austenite & \\
\hline \multirow[t]{2}{*}{$\sigma_{a}, \mathrm{MPa}$} & \multicolumn{2}{|c|}{$\sigma_{a}=f([M], \rho)$} & \\
\hline & $\begin{array}{l}0 \\
0\end{array}$ & $\begin{array}{l}35 \\
45\end{array}$ & {$[1,7]$} \\
\hline$c_{1}, \mathrm{MPa}$ & $\begin{array}{l}1100 \\
1080\end{array}$ & $\begin{array}{l}- \\
-\end{array}$ & {$[1,7]$} \\
\hline$c_{2}, \mathrm{MPa}$ & $\begin{array}{l}- \\
- \\
-\end{array}$ & $\begin{array}{l}1356 \\
1100\end{array}$ & {$[1,7]$} \\
\hline \multirow[t]{2}{*}{$c_{3}, \mathrm{~K}^{-1}$} & \multicolumn{2}{|c|}{$\begin{array}{l}c_{3}=\frac{k}{W_{0}} \ln \left(\frac{b \rho v_{0} \Delta l}{M}\right) \\
\rho=\rho_{o} B \exp (\varepsilon X)\left(\frac{A}{T-273}\right)^{s} \\
\left(\frac{A}{T-273}\right)^{s} \text { represents an effect of annihilation process } \\
\text { of dislocation activation during recovery process and } \\
\text { depends on the parameters reflecting the quality of } \\
\text { austenite and ferrite microstructure i.e. grain size, } \\
\text { inhomogeneity of grain size distribution }\end{array}$} & $\begin{array}{l}{[5]} \\
{[8]}\end{array}$ \\
\hline & $\begin{array}{l}0.00390 \\
0.00558\end{array}$ & $\begin{array}{l}0.00245 \\
0.00185\end{array}$ & {$[1,7]$} \\
\hline$c_{4}, \mathrm{~K}^{-1}$ & $\begin{array}{l}0.000280 \\
0.000225\end{array}$ & $\begin{array}{l}0.000178 \\
0.000150\end{array}$ & {$[1,7]$} \\
\hline$c_{5}, \mathrm{MPa}$ & $\begin{array}{l}336 \\
131\end{array}$ & $\begin{array}{l}- \\
-\end{array}$ & {$[1,7]$} \\
\hline$K, \mathrm{MPa} \cdot \mathrm{mm}^{0.5}$ & $\begin{array}{l}5 \\
18\end{array}$ & $\begin{array}{l}23 \\
5\end{array}$ & {$[1,7]$} \\
\hline$n$ & $\begin{array}{l}0.298 \\
0.228\end{array}$ & $\begin{array}{l}- \\
-\end{array}$ & {$[1,7]$} \\
\hline$\sigma_{p}, \mathrm{MPa}$ & $\sigma_{p}=\frac{0.538 G b f^{1 / 2}}{\kappa} \ln \left(\frac{\kappa}{2 b}\right)$ & - & [9] \\
\hline$\sigma_{s g}, \mathrm{MPa}$ & $\begin{array}{l}\sigma_{s g}=k_{s} l^{m} \\
k_{s} \frac{1.6 G \sqrt{b \theta}}{2 \pi(1-v)} \cong 2.1 \sqrt{\theta} \\
\sigma_{s g}=\varepsilon_{a} P\left(\frac{T_{S}}{T_{D}}-1\right)^{w}\end{array}$ & - & $\begin{array}{l}{[10]} \\
{[11]} \\
{[12]}\end{array}$ \\
\hline
\end{tabular}


Equation describing the precipitation strengthening $\left(\sigma_{p}\right)$ by modified Ashby-Orowan equation (see Tab. 2) is difficult to manipulate because it is necessary to estimate the size of the particles. The example of calculations of the precipitation strengthening is shown in Figure 6. In most practical metal forming processes of microalloyed steels, the effect of precipitation can be described correctly by using the dispersion strengthening contribution coefficient $K_{p}$ of the alloy [13]. However, the precipitation of niobium nitrides and carbides as well as complex titanium-niobium nitrides or carbonitrides can be significantly modified because of the change of the stored energy in dynamically deformed steel.

The limitation of dislocation motion and potentially increased significance of mechanical twinning lead to a better (from point of view of strengthening) dislocation arrangement in the final product. For example, the annihilation process of dislocations, typical for large plastic deformation, is reduced. As it was concluded by Leslie [14], in ferrite structure, strained at low temperature or at high strain rates, the edge components of dislocations can move at higher rates than screw components. Hence, elongated segments of the latter remain in the structure. These screw components are unable to cross-slip at low temperatures or high strain rates. Therefore, due to the lack of cross-slip, no cell structure is formed. This behavior can slow down the formation of the substructure, resulting in the increase of dislocation strengthening and finally increases hardness. Presented observations occur in wide range of strains (see Fig. 4).

The comparison of calculated and measured flow stresses is shown in Figure 7. Presented results reflect the ability of the modified Zerilli-Armstrong model to calculate the mechanical response of HSLA and Ti-IF steels under dynamic and quasi-static loading conditions. It can be noticed that the comparison indicates a good agreement between calculated and measured flow stresses. The presence of microalloyed elements and absence of solute $\mathrm{C}, \mathrm{N}$ in fully stabilized steels leads to significant differences in the mechanical behavior between Ti-IF and HSLA.

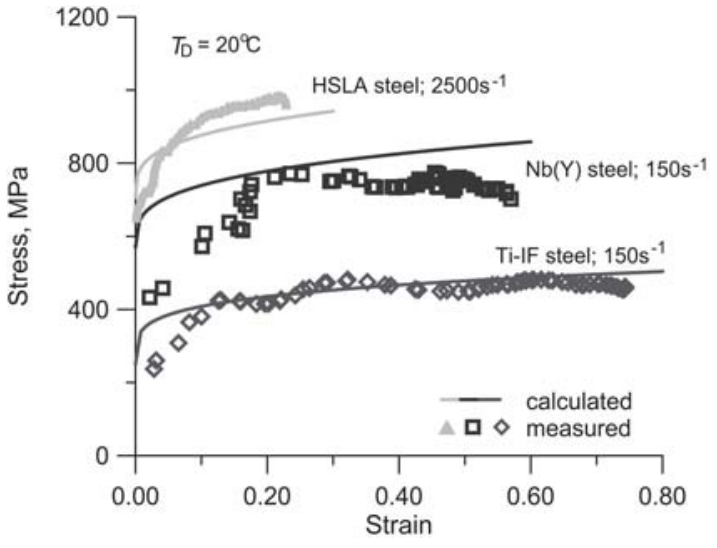

Fig. 7. Flow stress as predicted by model and measured during compression tests [15] 
The various metallurgical phenomena that influence the microstructure evolution and mechanical response of microalloyed steels under dynamic loading are difficult to determine experimentally. However, the preliminary analysis of present study enables to plan a very precise matrix of experiments in support of future modeling of the mechanisms of plastic flow and microstructure evolution under the dynamic loading conditions.

\section{CONCLUSIONS}

Basing on the analysis of this research the following observations can be formulated:

- High strain rate has strong influence on mechanical properties (increased hardness) of all investigated materials.

- Combining the microstructural evolution and modified Zerilli-Armstrong models allows accounting for inhomogeneities of the material mechanical and microstructural behavior during deformation with very high strain rates.

- Present studies showed that application of high strain rate causes more intensive cell structure formation comparing to statically deformed structures.

- Effect of high strain rate on ultrafine structures is more complex comparing to the "typical" structures. However, applying dynamic deformation offers new possibilities of improving the mechanical properties and ductility of final product.

The financial support of the Polish Committee for Scientific Research (research projects AGH No. 11.11.110.719) is gratefully acknowledged.

\section{REFERENCES}

[1] Stefańska-Kqdziela M., Majta J., Bator A., Muszka K.: Effects of Strain Rate and Microstructure Refinement on Mechanical Properties of IF and HSLA Steels. EUROMAT 2005, European Congress on Advanced Materials and Processes, 5-8 September 2005, Prague, Czech Republic

[2] Campbell J.D., Ferguson W.G.: The temperature and Strain-Rate Dependence of Shear Strength of Mild Steel. Philosophical Magazine, 21 (1970), 63-82

[3] Cowper G.R. el al:: Tech. Rep. 28 Brown University, 1957

[4] Johnson G.R., Cook W.H.: A constitutive model and data for metals subjected to large strains, high strain rates and high temperatures. Proceedings of the Seventh International Symposium on Ballistics, 1983, The Hague, Netherlands

[5] Zerilli F.J., Armstrong R.W.: Dislocation-mechanics-based constitutive relations for material dynamics calculations. Journal of Applied Physics, 61 (1987), 1816-1825

[6] Follansbee P.S., Kocks U.F.: A Constitutive Description of the Deformation of Copper Based on the use of the Mechanical Threshold Stress as an Internal State Variable. Acta Metallurgica, 36 (1988), 81-93

[7] Majta J., Stefańska-Kadziela M., Muszka K.: Modeling of strain rate effects on microstructure evolution and mechanical properties of HSLA and IF-Ti Steels. The 5th International Conference on HSLA Steels, HSLA Steels 2005, 8-10 November 2005, Sanya, Hainan, China. Proceedings in: Iron \& Steel Supplement, 40 (2005), 513-517

[8] Majta J., Zurek A.K.: Microstructure and deformation of microalloyed steels in the two-phase region. EPD Congress 2003, Extraction and Processing Division of The Minerals, Metals and Materials Society, M.E. Schlesinger (ed.), TMS, San Diego 2003, 63-81 
[9] Ashby M.F.: Oxide Dispersion Strengthening. G.S. Ansell, T.D. Cooper, F.V. (eds.), Lenel, Gordon and Breach, New York, 1958, 143

[10] Li J.C.M.: Trans. Metall. Soc. AIME, 227 (1963), 239

[11] Irvine J., Baker T.N.: The Influence of Rolling Variables on the Strengthening Mechanisms Operating in Niobium Steels. Materials Science and Engineering, 64 (1984), 124

[12] Majta J., Lenard J.G., Pietrzyk M.: A Study of the Effect of Thermomechanical History on the Mechanical Properties of a High Niobium Steel. Materials Science and Engineering A, 208A (1996), 249-259

[13] Hodgson P.D. et al.: A Mathematical Model to Predict the Mechanical Properties of Hot Rolled C-Mn and Microalloyed Steels. ISIJ Int., 32 (1992), 1329-1338

[14] Leslie W.C.: Microstructural Effects of High Strain Rate Deformation in Metallurgical Effects at High Strain Rates. The Metallurgical Society of AIME (1973), 571-580

[15] Majta J., Stefańska-Kadziela M., Muszka K., Bator A.: High strain rate behavior of microalloyed steels for automotive applications. 8th ICTP 2005, International Conference on Technology of Plasticity, October 913, 2005 Verona, Italy. CD

Received

May 2006 